Revista Destaques Acadêmicos, Lajeado, v. 12, n. 4, 2020. ISSN 2176-3070

DOI: http://dx.doi.org/10.22410/issn.2176-3070.v12i4a2020.2410

http://www.univates.br/revistas

\title{
INFLUÊNCIA DO TEOR DE CIMENTO NA RESISTÊNCIA À COMPRESSÃO SIMPLES DE UM SOLO RESIDUAL CIMENTADO ARTIFICIALMENTE
}

\author{
Thaise Canton Somensi ${ }^{1}$, Guilherme Togni ${ }^{2}$, Augusto Armani ${ }^{3}$, \\ Helena Batista Leon ${ }^{4}$, João Rodrigo Guerreiro Mattos ${ }^{5}$, \\ Emanuele Amanda Gauer ${ }^{6}$
}

Resumo: O solo é um material essencial para qualquer obra de engenharia, entretanto, o mesmo pode não apresentar os parâmetros solicitados em projeto. Em vista disso, inúmeros são os métodos para contornar esse problema, entre eles, a estabilização de solos. O presente artigo tem por finalidade avaliar e comparar o comportamento mecânico de uma mistura de um solo residual estabilizado com cimento. As amostras foram moldadas no sistema de triplicatas, com $50 \mathrm{~mm}$ de diâmetro e $100 \mathrm{~mm}$ de altura. Para as misturas, foram empregados duas massas específicas aparente secas $\left(\rho_{\mathrm{d}}\right)$ nos valores de 1,25 e 1,35 g/ $\mathrm{cm}^{3}$ e quatro diferentes teores de cimento, sendo eles $5 \%, 7 \%$, $9 \%$ e $11 \%$. A fim de realizar uma comparação, também foram moldados corpos de prova sem a adição de cimento. Após moldagem, todas as amostras permaneceram em cura durante 7 dias em câmara úmida, a uma temperatura de $23^{\circ} \mathrm{C} \pm 2{ }^{\circ} \mathrm{C}$, com umidade relativa do ar superior a $95 \%$. A fim de minimizar os efeitos de sucção, os corpos de prova foram colocados em imersão 24 horas antes de ser realizada a ruptura. A resistência das amostras foi obtida através do ensaio de resistência à compressão simples. Verificase que a resistência mecânica dos corpos de prova cresce com o aumento do teor de cimento adicionado nas misturas e da massa específica aparente seca de moldagem. Dessa forma, conclui-se que tanto a compactação como a adição do cimento CPV-ARI apresentaram um grande potencial para a estabilização do referido solo.

Palavras-chave: Estabilização de solos. Solo-cimento. Resistência à compressão.

1 Acadêmica do Curso de Engenharia Civil da Universidade do Vale do Taquari.

2 Acadêmico do Curso de Engenharia Civil da Universidade do Vale do Taquari.

3 Acadêmico do Curso de Engenharia Civil da Universidade do Vale do Taquari.

4 Engenheira Civil, Mestre, Professora da Universidade do Vale do Taquari.

5 Engenheiro Civil, Doutor, Professor da Universidade do Vale do Taquari.

6 Engenheira Civil, Doutora, Professora da Universidade do Vale do Taquari. 


\section{INTRODUÇÃO}

Segundo Consoli et al. (2007), o uso de técnicas tradicionais de engenharia geotécnica muitas vezes apresenta limitações devido ao custo elevado e/ou sustentabilidade ambiental. Por exemplo, a construção de rodovias com bases granulares torna-se inviável financeiramente quando a pedreira é longe da obra. Outro exemplo é a construção de fundações em solos que apresentam baixa capacidade de suporte, cujos custos de uma fundação profunda podem ser incompatíveis com o orçamento disponível para a construção.

Nesse contexto, uma alternativa viável para a melhoria do solo local é a estabilização química pela adição de cimento Portland. Internacionalmente, a técnica do solo-cimento é usada com sucesso em vários tipos de obras civis. Entretanto, no Brasil, não se vê a sua aplicação sendo muito difundida. Isso se justifica em parte devido ao fato de não existir uma metodologia de dosagem consolidada, como, por exemplo, existe para o concreto. A primeira experiência de campo relatada consiste na pavimentação de um trecho de 500 metros de extensão no acesso ao aeroporto de Bauru, onde o solo local foi estabilizado com um teor volumétrico de $11 \%$ de cimento Portland. Em seguida, foi pavimentado o acesso ao aeroporto de Presidente Prudente, com $14 \mathrm{~km}$ de extensão e teor de cimento variando entre $12 \%$ e $14 \%$ (SENÇO, 2001).

A estabilização com cimento Portland é adequada para uma grande variedade de solos, desde materiais granulares a materiais siltosos e argilosos, pois os efeitos da cimentação são decorrentes não apenas da interação aglomerante e solo, mas também das propriedades do próprio cimento, além de possuir a vantagem do rápido ganho de resistência. Em geral, a resistência à compressão simples aumenta com o incremento da quantidade de cimento, porém a taxa desse acréscimo depende do tipo de solo estabilizado. Estudos de Ingles e Metcalf (1972) apresentaram a influência do teor de cimento na resistência à compressão simples de alguns solos estabilizados com cimento Portland.

Consoli et al. (2011) afirmaram que a medida que ocorre a hidratação do cimento, a mistura de solo-cimento ganha resistência e as propriedades mecânicas do solo natural são aprimoradas. Os autores afirmam que as variáveis que controlam as propriedades e características das misturas de solo-cimento são o tipo de solo, o teor de cimento na dosagem, as condições de umidade e o grau de compactação. Ao estabilizar uma argila siltosa com teores de cimento variando entre $3 \%$ e $9 \%$ e massas específicas aparente secas entre $1,4 \mathrm{~g} / \mathrm{cm}^{3}$ e $1,67 \mathrm{~g} / \mathrm{cm}^{3}$ constataram uma relação diretamente proporcional do aumento da resistência à compressão simples com a adição de cimento. Os melhores resultados foram obtidos para as amostras ensaiadas $\operatorname{com} \rho_{\mathrm{d}}$ igual a $1,67 \mathrm{~g} / \mathrm{cm}^{3}$ e $9 \%$ de cimento.

Schnaid et al. (2001) também demonstraram que existe uma relação linear entre a resistência à compressão simples e o aumento do teor de cimento 
para solos granulares artificialmente cimentados, afirmando que a resistência à compressão simples é uma medida do grau de cimentação do solo.

Diante disto, este estudo tem como objetivo avaliar a influência do teor de cimento na resistência à compressão simples de um solo residual cimentado artificialmente. Para tanto, realizou-se a caracterização do solo estudado através dos ensaios de granulometria, massa específica dos grãos, limite de liquidez, limite de plasticidade e compactação. De posse dos resultados, definiu-se o teor de umidade e o valor da massa específica aparente seca para realizar as moldagens das misturas solo-cimento com diferentes teores de cimento.

\section{MATERIAL E MÉTODOS}

O material empregado na pesquisa consiste de diferentes dosagens de solo-cimento para verificar a influência do teor de cimento no ganho de resistência à compressão simples. Para tanto, empregou-se uma metodologia de pesquisa classificada como quantitativa, descritiva e experimental.

\subsection{Caracterização do solo}

O solo utilizado nesta pesquisa foi coletado no município de Lajeado-RS e trata-se de um solo residual de basalto, pertencente à formação Serra Geral. Streck et al. (2008) classificam este solo como um Chernossolo Háplico Órtico, que pode ser encontrado nas várzeas próximas dos rios que drenam a encosta inferior do nordeste do Rio Grande do Sul.

A coleta da amostra de solo foi realizada com o auxílio de equipamentos manuais de escavação, atentando para coletar uma amostra homogênea de material e que não fosse superficial para evitar a presença de matérias orgânicas da vegetação. Na Figura 1, apresenta-se um mapa de situação indicando o município de Lajeado, junto com um de localização apontando o local em que foi realizada a coleta do solo. 
Figura 1 - Local de extração do solo residual.

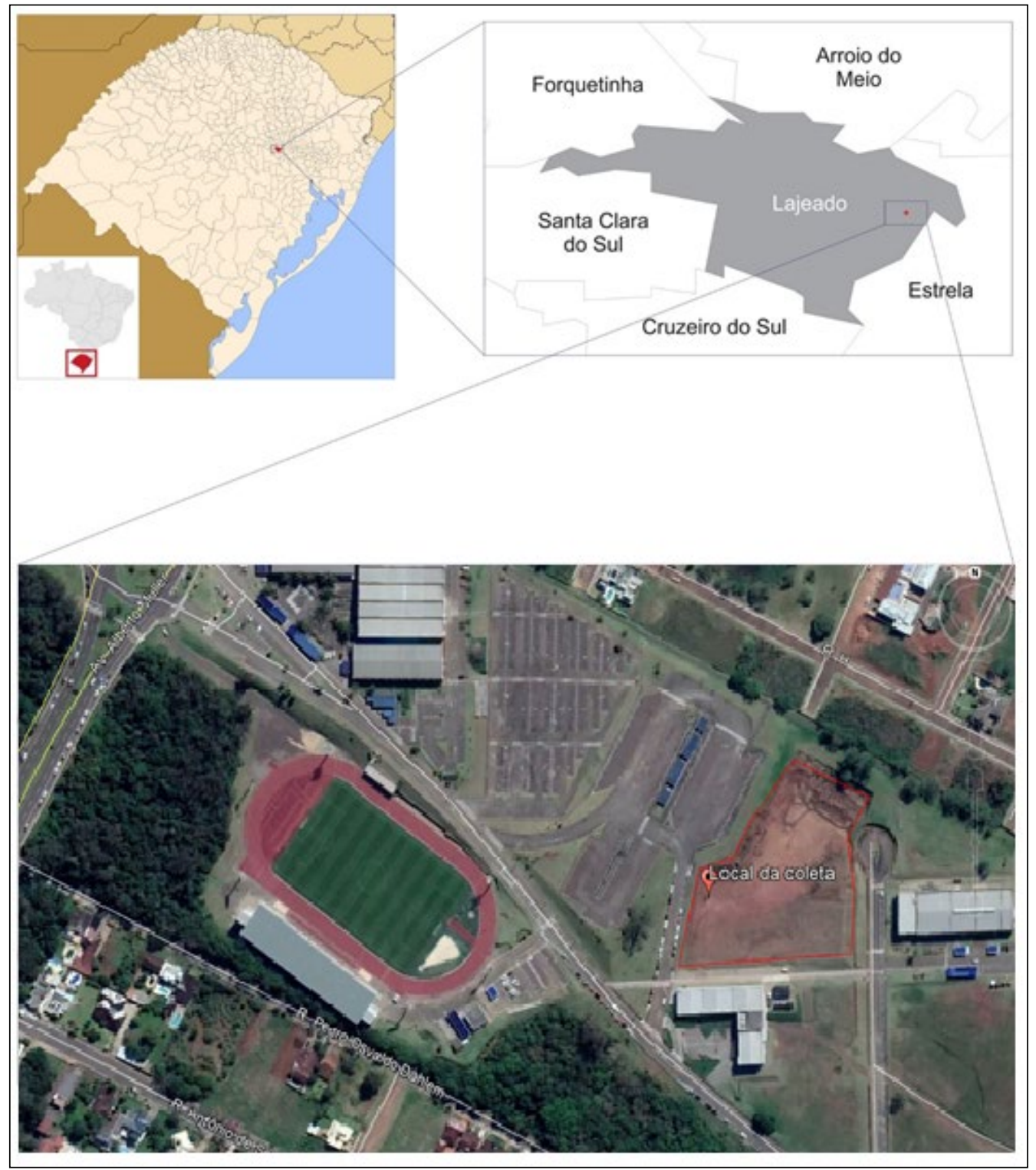

Fonte: Elaborado pelos autores (2019).

A análise granulométrica do solo foi realizada pelo peneiramento (fino e grosso) e sedimentação, conforme o procedimento descrito na NBR 7181 (ABNT, 2016a). A Figura 2 mostra a curva granulométrica do solo residual de Lajeado, pela qual, percebe-se que ele é formado predominantemente por solo fino, ou seja, por grãos com dimensões inferiores a 0,075 $\mathrm{mm}$. 
Figura 2 - Curva granulométrica do solo residual de Lajeado-RS.

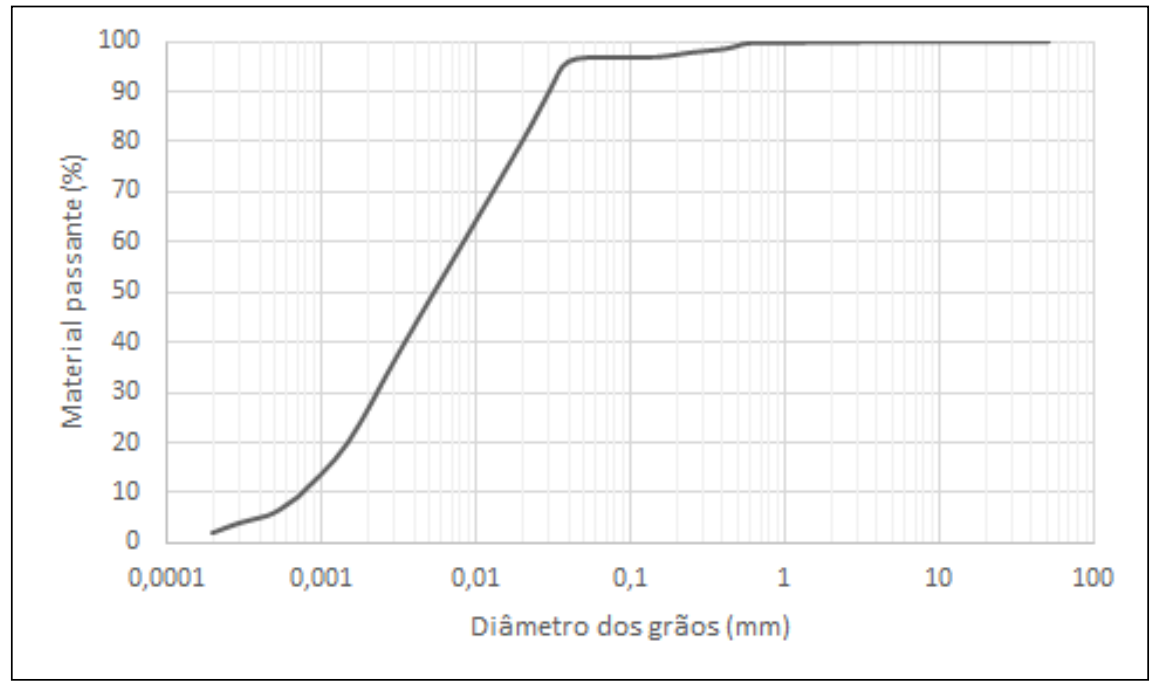

Fonte: Elaborado pelos autores (2019).

Como pode ser observado na curva granulométrica da Figura 2, o solo estudado é composto por $4 \%$ de areia, $70 \%$ de silte e $26 \%$ de argila. A massa específica dos grãos ( $\rho$ s), obtida conforme descrito na NBR 6458 (ABNT, 2017a), apresenta o valor de $2,857 \mathrm{~g} / \mathrm{cm}^{3}$.

Quanto aos limites de liquidez (LL) e de plasticidade (LP), expressos em números inteiros, seguiu-se o especificado na NBR 6459 (ABNT, 2017b) e NBR 7180 (ABNT, 2016b), respectivamente. A Figura 3 mostra o número de golpes aplicados até que as bordas inferiores da ranhura realizada no solo se unam ao longo de, aproximadamente, $13 \mathrm{~mm}$ de comprimento para diferentes teores de umidade. Enquanto que, na Tabela 1, apresentam-se os teores de umidade com os quais foram possíveis moldar um cilindro com diâmetro de $3 \mathrm{~mm}$. 
Figura 3 - Gráfico do limite de liquidez para o solo residual de Lajeado-RS.

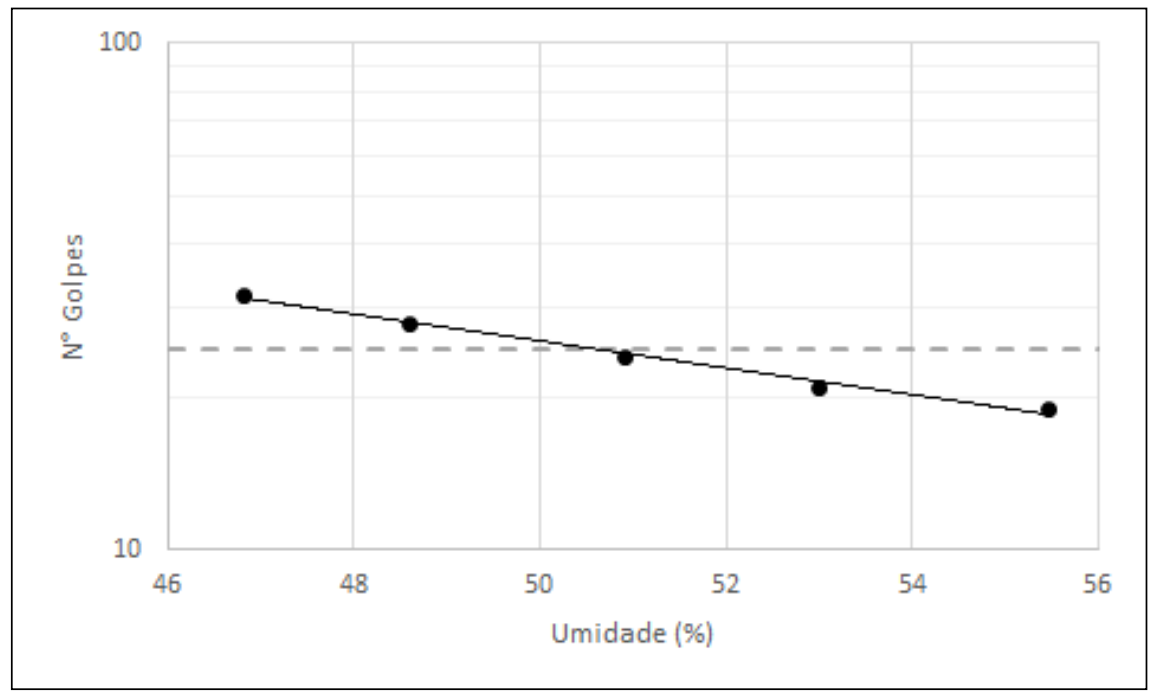

Fonte: Elaborado pelos autores (2019).

Ajustando uma reta pelos pontos obtidos no ensaio, o LL do solo é o teor de umidade correspondente a 25 golpes. Dessa forma, conforme a Figura 3, o LL do solo de Lajeado é igual a 51\%.

Tabela 1 - Teores de umidades do limite de plasticidade para o solo residual de Lajeado-RS, 2019

\begin{tabular}{lll}
\hline Ensaio & Umidade & Média \\
\hline 1 & 45,13 & \\
2 & 45,16 & 45,29 \\
3 & 45,59 & \\
\hline
\end{tabular}

Fonte: Elaborado pelos autores (2019).

O LP do solo corresponde ao teor de umidade médio de, no mínimo, três ensaios que não podem apresentar uma variação maior do que $\pm 5 \%$ da média. De acordo com a Tabela 1, o LP do solo de Lajeado é igual a $45 \%$.

O índice de plasticidade (IP), que é a diferença entre o LL e LP, tem o valor de $6 \%$. Portanto, como o IP é inferior a 7\%, a argila presente no solo é fracamente plástica. Quanto ao índice de atividade (IA), dado pela razão entre o IP e o percentual de argila, o solo de Lajeado apresenta o valor de 0,23. Como o IA é inferior a 0,75 , entende-se que a argila presente no solo é dita inativa. Tal 
fato, contribuiu para a escolha da utilização de cimento para estabilizar o solo estudado.

Tendo conhecimento da granulometria, LL e IP, foi possível a classificação do solo pelos métodos Highway Research Board (HRB) e Sistema Unificado de Classificação de Solos (SUCS). Utilizando a classificação HRB, constatou-se que o solo utilizado pertence ao grupo A-5, enquanto que, através do SUCS, o solo enquadra-se na classificação do tipo MH (Mo High Liquid Limit). Assim, o solo utilizado na pesquisa é siltoso com pequena quantidade de argila de alta compressibilidade.

Por fim, realizou-se o ensaio de compactação, conforme a NBR 7182 (ABNT, 2016c). No ensaio, foi empregada a energia normal de compactação, que consiste em aplicar 26 golpes para cada uma das três camadas compactadas do corpo de prova (CP). Na Figura 4, observa-se a curva de compactação do solo de Lajeado.

Figura 4 - Curva de compactação para o solo residual de Lajeado-RS

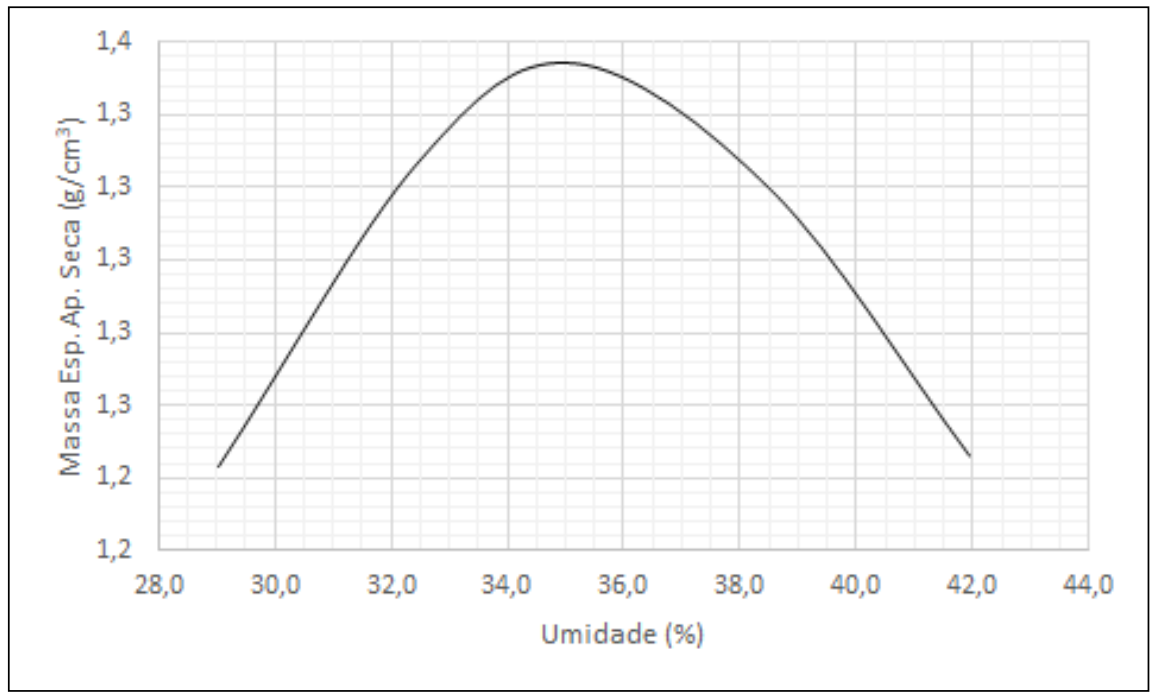

Fonte: Elaborado pelos autores (2019).

A partir da curva de compactação, pode-se observar que o teor de umidade ótimo $\left(\mathrm{w}_{6 \mathrm{ot}}\right)$ para compactação é de $35 \%$ e a massa específica aparente seca máxima $\left(\rho_{\mathrm{d} \text {,máx }}\right)$ é de $1,354 \mathrm{~g} / \mathrm{cm}^{3}$. Sabe-se que, com a adição de cimento, esses valores podem sofrer uma pequena variação, entretanto, foram utilizados os parâmetros de compactação do solo puro em todas as misturas de solocimento estudadas para evitar a inserção de outras variáveis na análise. Dessa forma, definiu-se que seriam moldados corpos de prova (CPs) com dois valores de massa específica aparente seca $\left(\rho_{\mathrm{d}}\right)$, a saber: $1,25 \mathrm{~g} / \mathrm{cm}^{3}$ e $1,35 \mathrm{~g} / \mathrm{cm}^{3}$, ambos com o teor de umidade de $35 \%$. 


\subsection{Cimento}

O cimento utilizado na pesquisa foi o CPV-ARI (cimento Portland de alta resistência inicial), que foi escolhido devido a sua alta reatividade em poucos dias de cura e pelo seu grau de moagem que proporciona um maior rendimento à mistura com o solo. O CPV-ARI possui, no máximo, 3,5\% de resíduo insolúvel, 4,5\% de óxido sulfúrico (SO3) e 6,5\% de óxido de magnésio $(\mathrm{MgO})$. Além disso, não possui adição de escória e nem de material pozolânico.

\section{3 Água}

A água utilizada neste estudo é potável e proveniente da rede de abastecimento pública do município de Lajeado/RS. A quantidade de água em cada mistura foi calculada em função da umidade ótima do solo utilizado.

\subsection{Programa experimental}

O programa experimental empregado na pesquisa consiste na dosagem das misturas solo-cimento, moldagem, processo de cura e ruptura dos CPs.

\subsubsection{Dosagem das misturas de solo cimento}

As porcentagens de cimento utilizadas nas misturas foram definidas a partir do estudo de Jung et al. (2012), que, segundo os autores, representam a experiência brasileira e internacional com solo-cimento. Portanto, empregouse os teores de $5 \%, 7 \%, 9 \%$ e $11 \%$ para compor as misturas analisadas. Além disto, foram moldados corpos de prova apenas com solo, ou seja, sem adição de cimento, para utilizar como referência.

A quantidade de cimento adicionado é um percentual referente à massa do solo seca. Já a quantidade de água é calculada em relação à massa seca total da mistura solo-cimento. A massa total da mistura deve ser suficiente para a moldagem de um CP e para a coleta de uma amostra, com a qual se controla o teor de umidade durante a compactação.

As variáveis estudadas foram dois valores de $\rho_{\mathrm{d}}$ para o solo puro e quatro teores de adição de cimento. Para cada dosagem, moldaram-se CPs em triplicata. Assim sendo, o programa experimental consiste na moldagem de um total de $30 \mathrm{CPs}$. Com as dosagens propostas foi possível identificar a influência do teor de cimento na resistência à compressão simples das misturas solo-cimento estudadas.

\subsubsection{Moldagem dos corpos de prova}

A moldagem dos CPs foi realizada em um cilindro de ferro fundido tripartido, com as dimensões de $50 \mathrm{~mm}$ de diâmetro e $100 \mathrm{~mm}$ de altura. A confecção dos CPs consiste nos procedimentos de pesagem, mistura, 
compactação e desmoldagem. Após a pesagem dos materiais que compõem a mistura em balança com precisão de $0,01 \mathrm{~g}$, mistura-se primeiro o solo com o cimento até obtenção de uma mistura com coloração homogênea e, em seguida, adiciona-se a água e, novamente, mistura-se para homogeneizar.

Após a mistura dos materiais, divide-se a massa necessária para a moldagem de um $\mathrm{CP}$ em três partes iguais para ser compactada estaticamente com o auxílio de uma prensa manual. O processo de compactação pode ser visto na Figura 5.

Figura 5 - Compactação estática do CP de solo-cimento

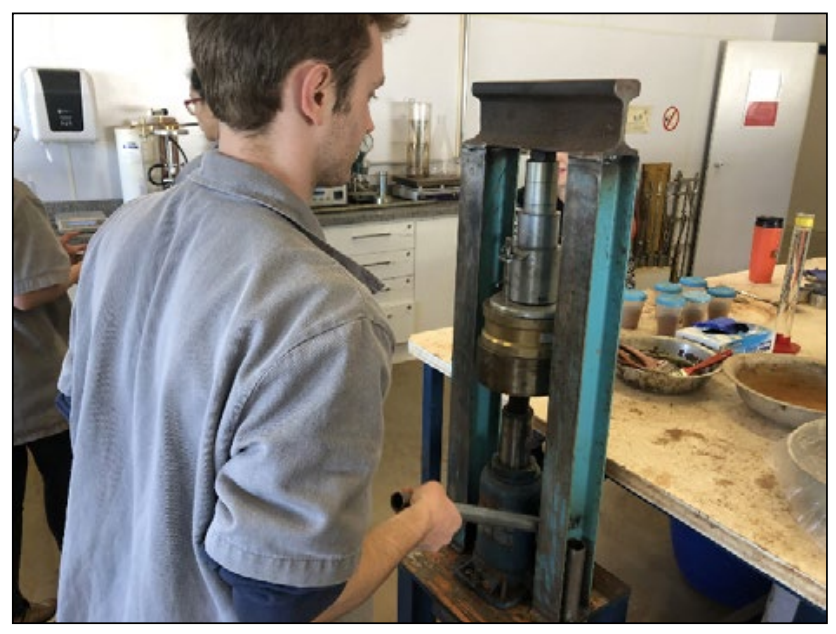

Fonte: Elaborado pelos autores (2019).

Após a conclusão da compactação estática, o CP deve ser desmoldado para pesagem e medição com precisão de 0,001 g e 0,1 mm, respectivamente. Para validar a moldagem, empregou-se as tolerâncias propostas por Dalla Rosa (2009), que consistem em: grau de compactação entre $99 \%$ e $101 \%$ em relação a $\rho_{\mathrm{d} \text {,máx }}$ do solo, dimensões com tolerância de $\pm 0,5 \mathrm{~mm}$ no diâmetro e $\pm 1,0 \mathrm{~mm}$ na altura. Além disso, aceitou-se uma variação de $\pm 2 \%$ em relação a $w_{\text {ot }}$ do solo. Todos os CPs que não atenderem a um ou mais desses critérios de tolerâncias previamente estabelecidos foram moldados novamente para se adequarem. Com isso, mitigou-se a dispersão dos resultados obtidos no conjunto da triplicata.

\subsubsection{Cura dos corpos de prova}

Os CPs foram curados durante 7 dias em câmara úmida, este período de cura foi definido em função do cimento adotado ser do tipo CPV-ARI. Faz-se necessário a cura ocorrer num ambiente com temperatura e umidade controladas para não afetar as reações químicas das misturas e influenciar nos 
resultados. Então, a câmara úmida foi ajustada para temperatura de $23^{\circ} \mathrm{C} \pm 2{ }^{\circ} \mathrm{C}$ e umidade relativa do ar superior a $95 \%$.

Com o intuito de aproximar a mistura solo-cimento à condição de saturada, 24 horas antes do término da cura, ou seja, antes da ruptura, os CPs foram imersos num recipiente com água. Dessa forma, foi desconsiderada a contribuição da suç̧ão matricial na resistência das misturas. Conforme pode ser observado na Figura 6, os CPs foram submersos no recipiente de modo a se obter uma lâmina d'água de, aproximadamente, $1,0 \mathrm{~cm}$ acima do seu topo.

Figura 6 - Imersão dos CPs de solo-cimento

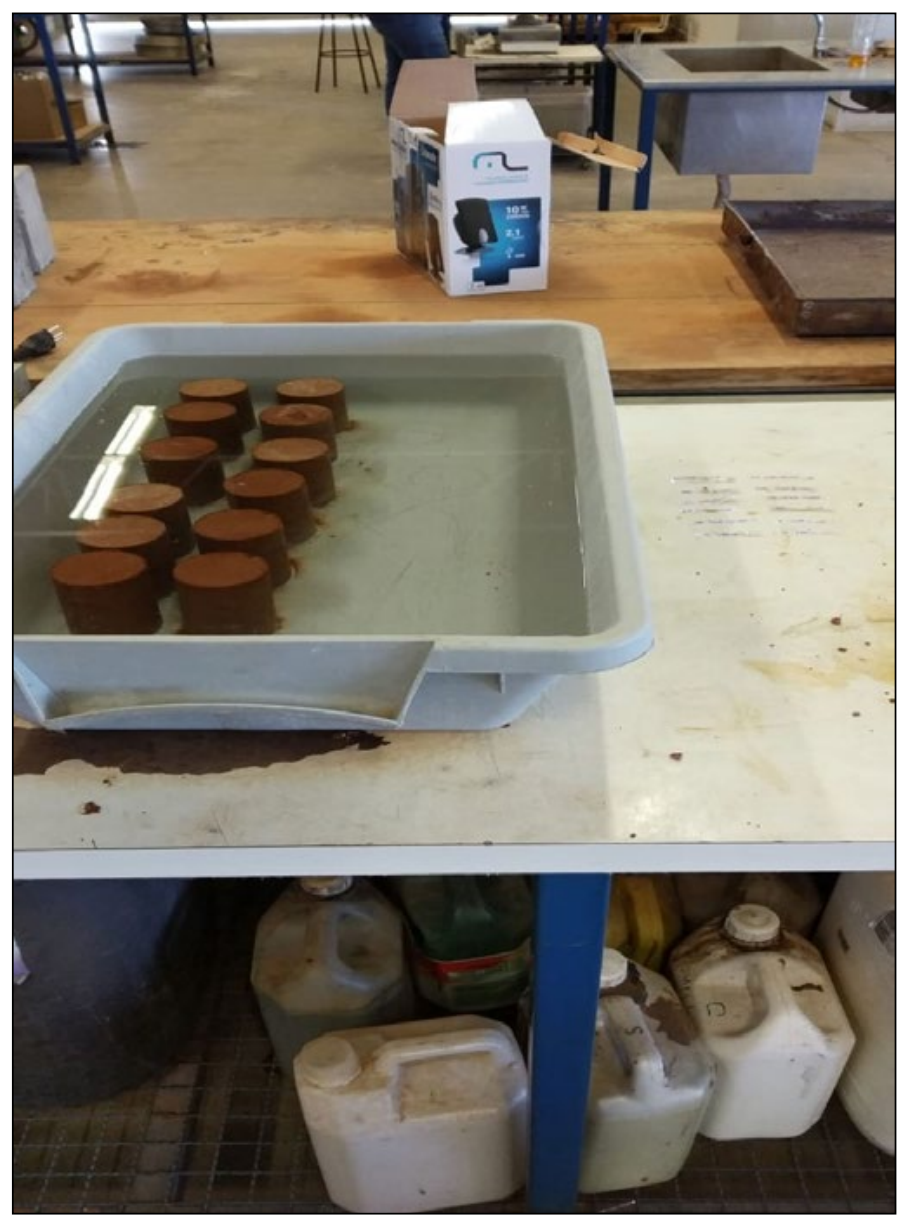

Fonte: Elaborado pelos autores (2019).

\subsubsection{Ruptura dos corpos de prova}

A resistência à compressão simples é a principal etapa desta pesquisa e tem como objetivo analisar a influência do teor de cimento empregado 
nas misturas. Os CPs foram rompidos à compressão simples numa prensa universal de ensaios, automática, cuja capacidade da célula de carga é de $50 \mathrm{kN}$. A velocidade de deformação empregada no ensaio foi de $1,14 \mathrm{~mm} /$ minuto. A resistência à compressão simples da mistura consiste na maior tensão axial que o CP suporta antes de romper. A Figura 7 mostra o procedimento de ruptura dos CPs de solo-cimento.

Figura 7 - Ruptura do CP solo-cimento

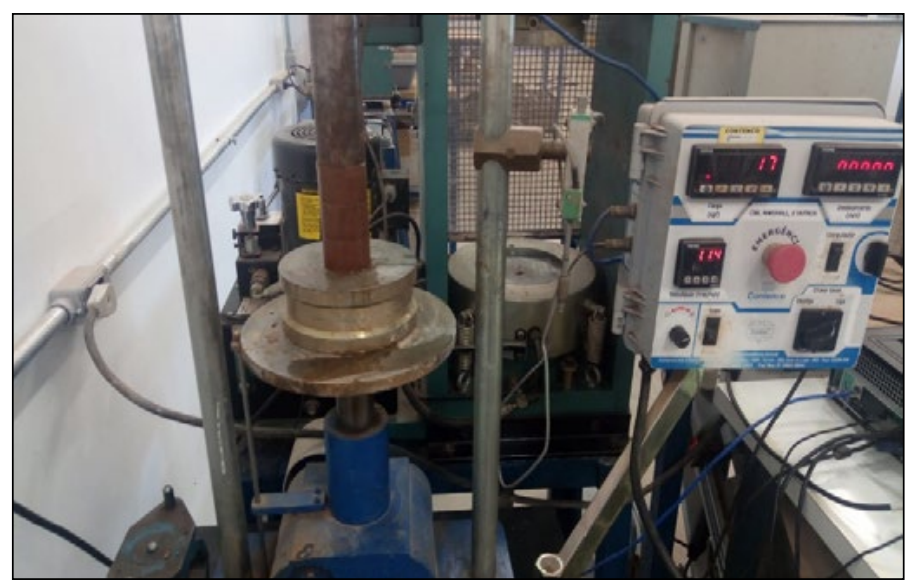

Fonte: Elaborado pelos autores (2019).

\section{RESULTADOS E DISCUSSÃO}

Esta pesquisa consiste em avaliar a influência do teor de cimento na resistência à compressão simples de um solo residual artificialmente cimentado.

A partir dos resultados obtidos pelo programa experimental proposto, as Tabelas 2 e 3 mostram os valores de resistência à compressão simples obtidos e a análise do coeficiente de variação $(\mathrm{CV})$ para as amostras ensaiadas com $\rho_{\mathrm{d}}$ de 1,25 e $1,35 \mathrm{~g} / \mathrm{cm}^{3}$, respectivamente. Enquanto que a Figura 8 apresenta a relação entre a resistência à compressão simples $\left(\mathrm{q}_{\mathrm{u}}\right)$ e o teor de cimento (ci). 
Tabela 2 - Resultados de resistência à compressão simples para $\rho_{\mathrm{d}}$ de 1,25 g/ $\mathrm{cm}^{3}$

\begin{tabular}{lllll}
\hline ci $(\%)$ & $\mathrm{q}_{\mathrm{u}}(\mathrm{kPa})$ & Média $(\mathrm{kPa})$ & $\begin{array}{l}\text { Desvio Padrão } \\
(\mathrm{kPa})\end{array}$ & $\mathrm{CV}(\%)$ \\
\hline 0 & 20,12 & & & \\
0 & 25,38 & 21,84 & 3,06 & 14,03 \\
0 & 20,03 & & & \\
5 & 99,29 & & 15,93 & 13,80 \\
5 & 131,14 & 115,39 & & \\
5 & 115,74 & & & \\
7 & 327,21 & & & \\
7 & 321,54 & 334,05 & 16,99 & \\
7 & 353,39 & & & \\
9 & 896,00 & & 75,33 & \\
9 & 1019,68 & 933 & & \\
9 & 883,32 & & & \\
11 & 1291,95 & & 122,25 & 9,32 \\
11 & 1201,21 & 1312,12 & & \\
11 & 1443,21 & & & \\
\hline
\end{tabular}

Fonte: Elaborado pelos autores (2019).

Tabela 3 - Resultados de resistência à compressão simples para $\rho_{\mathrm{d}}$ de 1,35 g/ $\mathrm{cm}^{3}$

\begin{tabular}{lllll}
\hline ci $(\%)$ & $\mathrm{q}_{\mathrm{u}}(\mathrm{kPa})$ & Média $(\mathrm{kPa})$ & $\begin{array}{l}\text { Desvio Padrão } \\
(\mathrm{kPa})\end{array}$ & $\mathrm{CV}(\%)$ \\
\hline 0 & 110,10 & & & \\
0 & 101,74 & 102,81 & 6,82 & 6,63 \\
0 & 96,56 & & & \\
5 & 214,60 & & & \\
5 & 243,47 & 235,45 & 18,21 & 7,73 \\
5 & 248,26 & & & \\
7 & 650,86 & & & \\
7 & 733,77 & 727,20 & 73,28 & 10,08 \\
7 & 796,96 & & & \\
9 & 1360,19 & & & 12,71 \\
9 & 1522,00 & 1353,43 & 172,05 &
\end{tabular}




\begin{tabular}{lllll}
\hline ci $(\%)$ & $\mathrm{q}_{\mathrm{u}}(\mathrm{kPa})$ & Média $(\mathrm{kPa})$ & $\begin{array}{l}\text { Desvio Padrão } \\
(\mathrm{kPa})\end{array}$ & $\mathrm{CV}(\%)$ \\
\hline 11 & 1777,34 & & & \\
11 & 1882,83 & 1853,41 & 66,44 & 3,58 \\
11 & 1900,05 & & & \\
\hline
\end{tabular}

Fonte: Elaborado pelos autores (2019).

Com base nas Tabelas 2 e 3, verifica-se que todas as triplicatas das dosagens apresentaram CV menor ou igual a $15 \%$, o que significa que os grupos de amostras analisados possuem baixa dispersão. Logo, os dados são, estatisticamente, homogêneos, então não é necessário a exclusão de nenhum deles para realizar a análise.

A Figura 8 apresenta o gráfico que relaciona a resistência à compressão simples com o teor de cimento empregado nas misturas. Nela pode-se observar que o teor de cimento tem influência na resistência à compressão simples do solo, visto que $\mathrm{q}_{\mathrm{u}}$ aumenta linearmente com o aumento do teor de cimento para ambas as massas específicas aparente secas, com coeficientes de determinação $\left(\mathrm{R}^{2}\right)$ de 0,98 e 0,96 , indicando um ótimo ajuste aos dados analisados. Visualizase, ainda, que, para as amostras com $\rho_{\mathrm{d}}$ de $1,35 \mathrm{~g} / \mathrm{cm}^{3}$, a taxa de crescimento de $\mathrm{q}_{\mathrm{u}}$ com o aumento do teor de cimento (inclinação da reta de ajuste dos dados) é maior do que para as amostras com $\rho \mathrm{d}$ de $1,25 \mathrm{~g} / \mathrm{cm}^{3}$.

Figura 8 - Influência do teor de cimento na resistência à compressão simples.

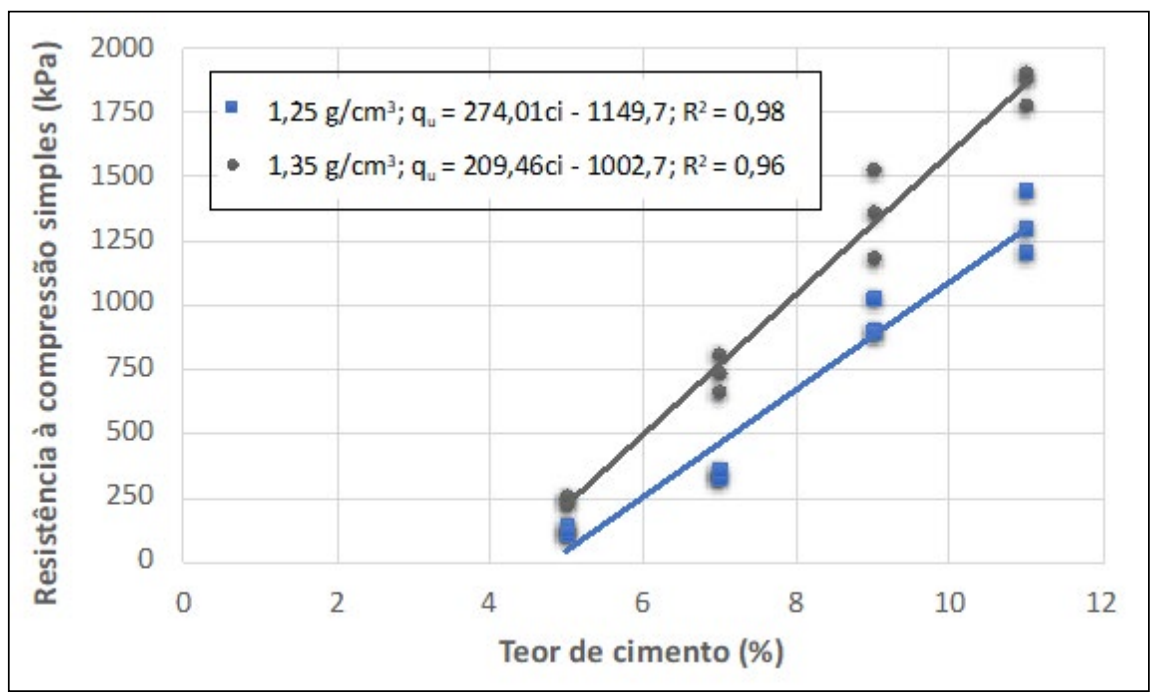

Fonte: Elaborado pelos autores (2019). 
Nas amostras com $\rho_{\mathrm{d}}$ de $1,25 \mathrm{~g} / \mathrm{cm}^{3}$, a adição de $11 \%$ de cimento resultou em um aumento de quase 11 vezes no valor da resistência à compressão simples das amostras, em comparação com a adição de $5 \%$ de cimento. Já, se considerar o solo compactado sem cimento ( $0 \%$ de teor de cimento), o aumento na resistência, comparando com o solo com $11 \%$ de cimento, foi de 60 vezes. Já para as amostras com $\rho_{\mathrm{d}}$ de $1,35 \mathrm{~g} / \mathrm{cm}^{3}$, a adição de $11 \%$ de cimento resultou em um aumento de quase 8 vezes no valor da resistência à compressão simples das amostras, em comparação com a adição de $5 \%$ de cimento. Já, se considerar o solo compactado sem cimento ( $0 \%$ de teor de cimento), o aumento na resistência foi de 18,5 vezes, o que evidencia o ganho de resistência com o aumento no teor de cimento.

Ainda, comparando as duas massas específicas utilizadas nas moldagens dos CPs, observa-se que o aumento da massa específica aparente seca ocasiona um aumento na resistência. Para $11 \%$ de cimento, o aumento de resistência com o aumento de $\rho_{\mathrm{d}}$ foi de, aproximadamente, $50 \%$.

\section{CONSIDERAÇÕES FINAIS}

Os resultados obtidos nesta pesquisa evidenciaram a influência do teor de cimento na resistência à compressão simples do solo residual artificialmente cimentado. Além disso, também verificou-se a importância da compactação, ou seja, da massa específica aparente seca.

Com as análises realizadas, foi demonstrado que o solo residual do município de Lajeado-RS, predominantemente com granulometria de silte, possui um ganho de resistência linear com a adição de cimento. Comparando os resultados de resistência à compressão simples do solo puro e da mistura de solo com $11 \%$ de cimento, obteve-se um ganho de 60 e 18,5 vezes para as massas específicas aparente secas de $1,25 \mathrm{~g} / \mathrm{cm}^{3} \mathrm{e} 1,35 \mathrm{~g} / \mathrm{cm}^{3}$, respectivamente.

Quanto à massa específica aparente seca das moldagens, observouse que o maior valor resultou numa tendência de aumento mais acentuada, maior inclinação da reta de ajuste dos dados. Também verificou-se que, para $11 \%$ de cimento, o aumento da massa específica aparente seca resultou em, aproximadamente, $50 \%$ a mais de resistência.

\section{REFERÊNCIAS}

ASSOCIAÇÃO BRASILEIRA DE NORMAS TÉCNICAS. NBR 6458: Grãos de pedregulho retidos na peneira de abertura $4,8 \mathrm{~mm}$ - Determinação da massa específica, da massa específica aparente e da absorção de água. Rio de Janeiro: ABNT, 2016 versão corrigida 2: 2017. 10 p.

ASSOCIAÇÃO BRASILEIRA DE NORMAS TÉCNICAS. NBR 6459: Solo Determinação do limite de liquidez. Rio de Janeiro: ABNT, 2016 versão corrigida 2: 2017. 9 p. 
ASSOCIAÇÃO BRASILEIRA DE NORMAS TÉCNICAS. NBR 7180: Solo Determinação do limite de plasticidade. Rio de Janeiro: ABNT, 2016b. 7 p.

ASSOCIAÇÃO BRASILEIRA DE NORMAS TÉCNICAS. NBR 7181: Solo - Análise granulométrica. Rio de Janeiro: ABNT, 2016a. 12 p.

ASSOCIAÇÃO BRASILEIRA DE NORMAS TÉCNICAS. NBR 7182: Solo - Ensaio de compactação. Rio de Janeiro: ABNT, 2016b. 9 p.

CONSOLI, Nilo C.; FOPPA, Diego; FESTUGATO, Lucas; HEINECK, Karla S. Key Parameters for Strength Control of Artificially Cemented Soils. Journal of Geotechnical and Geoenvironmental Engineering, (Local), v. 133, n. 2, p. 197-205, fev. 2007.

CONSOLI, Nilo Cesar et al. Porosity-Cement Ratio Controlling Strength of Artificially Cemented Clays. Journal Of Materials In Civil Engineering, [s.1.], v. 23, n. 8, p.12491254, ago. 2011.

DALLA ROSA, A. Estudo dos parâmetros-chave no controle da resistência de misturas solo-cinza-cal. 2009. Dissertação (Mestrado em Engenharia Civil - Programa de Pós-Graduação em Engenharia Civil): Universidade Federal do Rio Grande do Sul, 2009.

INGLES, O. G.; METCALF, J. B. Soil Stabilization: Principles and Practice. Sydney: Butterworths, 1972. $374 \mathrm{p}$

JUNG, Jonatan G.; STRACKE, Fernanda; KORF, Eduardo P.; Consoli, Nilo C. A influência do tipo de cimento na resistência à compressão simples de uma areia artificialmente cimentada. Revista Luso-Brasileira de Geotecnia, São Paulo, n. 125, p. 87-94, jul. 2012.

SCHNAID, F.; PRIETTO, P. D. M.; CONSOLI, N. C. Characterization of cement sand in triaxial compression. Journal of Geotechnical and Geoenvironmental. New York, V.127, p. 857-868, 2001

SENÇO, W. de. Manual de Técnicas de Pavimentação: v. 2. São Paulo: Pini, 2001. 672 p.

STRECK, Edemar Valdir; KÄMPF, Nestor; KLAMT, Egon; SCHNEIDER, Paulo; NASCIMENTO, Paulo C. do; GIASSON, Élvio; PINTO, Luiz F. S.; DALMOLI, Ricardo S. D. Solos do Rio Grande do Sul. 2.ed. Porto Alegre: EMATER/RS, 2008. 222p 